\title{
Coordination in Brazilian Pharmaceutical Supply Chains
}

\author{
Priscila Laczynski de Souza Miguel \\ plsmiguel@gmail.com \\ FGV-EAESP \\ Manuel de Andrade e Silva Reis \\ manoel.reis@fgv.br \\ FGV-EAESP
}

A B STRACT: Supply chain coordination (SCC) can be a challenge for many organizations as different firms in the same chain has different expectations and interdependencies (Arshinder \& Deshmukh, 2008). Lack of SCC can result in the bullwhip effect and poor performance for a firm and its partners. By investigating the phenomenon in the Brazilian pharmaceutical supply chain using a qualitative research, this paper aims to understand the main issues that avoid a better integrated chain. Results of 21 interviews suggested that the lack of coordination in this environment was influenced by the network design and the history of the sector in Brazil, as well as scarce resources.

Key words: coordination, pharmaceutical supply chain, interorganizational relationships, bullwhip effect. 


\section{INTRODUCTION}

Demand management (DM) is the Supply Chain Management (SCM) process responsible for balancing the productive capacity and the demand of a company, as well as the whole chain, synchronizing supply and demand between the upstream and downstream organizations. DM can contribute to firm performance, by reducing operational costs and inventories and increasing customer satisfaction and can only be effective if supply chain coordination (SCC) exists.

Supply chain Coordination (SCC) is a key construct in the Operations and Supply Chain Management field, although there is still no consensus on how it can be defined and its knowledge is still under development (Arshinder \& Deshmukh, 2008). An effective management of activities and flow of goods requires that all individuals and organizations are aligned with supply chain goals and therefore, their actions should be coordinated (Fugate et al. (2006). According to Lee et al. (1997), the lack of coordination can result in the amplification of demand variability in a chain, also known as bullwhip effect that has been studied in the academic field since the seminal work of Forrester (1961).

Despite the successful cases, SCC is not a common practice, as managers face some challenges to extend coordination from within the organization to intraorganizational relationships: dominant member in the chain that takes decisions, different organizational culture, lack of coherent contracts, lack of meetings and commitment, incompatible information systems, conflicting objectives, independent cost evaluation of activities and processes, etc (Arshinder \& Deshmukh, 2008). The former difficulties, however, disregard some important aspects of a supply chain that can result in obstacles for coordination, such as historical evolution of a supply chain and institutional aspects.

Therefore, this study aims to contribute to a deeper understanding of coordination barriers by investigating the reasons for the lack of coordination in the Brazilian pharmaceutical supply industry, that operates in the country since the beginning of 1900s and was affected by new regulations in the last 20 years as well as the entrance of new players.

Based on 21 qualitative interviews conducted with several organizations in the chain (suppliers, industry, distributors, drugstores, service providers and nodes representative associations), results suggested that lack of cooperation is a consequence of a chain that is highly influenced by the Brazilian institutional environment, low trust level between partners and lack of qualified professionals in the industry. The environment is highly regulated, resulting in few participants with high influence over the other echelons. Findings also provided evidence that the chain is not coordinated in an integrative way, but supply and demand are managed independently, with almost no information exchange.

The paper is structured as follows. Initially, the Literature Review section presents important references on supply chain management, demand management and coordination. Next, the methodology is presented and data analysis and key findings are discussed. The last section presents the main conclusions of the study, including its limitations and opportunities for future research.

\section{LITERATURE REVIEW}

\subsection{The Supply Chain and Supply Chain Management}

A supply chain is a sequence of activities, involving supply, manufacturing and distribution between many organizations, aiming to deliver value to a final consumer (Mentzer et al, 2001). Depending on the relationships between any dyad in a supply chain, companies adopt different governance mechanisms (from an arm's length to a more collaborative perspective) in order to maximize their benefits (Jarillo, 1988).

A more collaborative approach, also known as supply chain management (SCM), assumes partnerships between members of a chain, resulting in firm and overall performance improvements. The SCM assumes process integration, long-term relationships based on trust and commitment, collaboration in projects and processes and strategic information sharing between two or more organizations (Cooper et al, 1997; Cooper \& Ellram, 1993; Mentzer et al., 2001). Although there is a discussion if SCM should be considered at the activity level (Lambert et al, 1998) or if it is a strategic and systemic approach (Mentzer et al, 2001), authors agree on the business process that should be considered: Customer Relationship Management, Customer Service Management, Demand Management, Order Fulfillment, Manufacturing Flow Management, Procurement, Product and Process Development and Reverse Logistics. The focus of the present research is on de- 
mand management process that is responsible for balancing demand and capacity in a supply chain.

\subsection{Demand Management and the Bullwhip Effect}

One of the key processes of supply chain management is demand management, responsible for balancing the demand and capacity of a firm and also the chain (Lambert and Cooper; Pagh, 1998). This process aims to balance the needs of customers with the operations of a firm and includes demand forecasting and synchronization between production, procurement and distribution, allowing the company to be more proactive for forecasted sales and react quickly and efficiently in case of unexpected demand (Croxton et al., 2002).

Taylor (2006, p. 164) defined demand management as:

the study of the structure and efficacy of the information channels and procedures used to handle demand throughout the length of the supply chain, both internally within companies and externally between companies. It also includes detailed analysis of the nature of the demand information that is passed along these channels, including forecasts, orders, amendments and reconciliations.

DM has been studied since the seminal work of Forrester (1961) about industrial dynamics that stated that variations in production rates in companies are usually larger than the fluctuations in demand of final consumers. This difference would be caused by the amplification of small disturbances, as well as by the lack of information along the chain.

If processes within and among organizations are coordinated properly, the so-called "bullwhip effect" and therefore, the company's operational costs can be reduced (Metters, 1997; Lee et al., 1997). The bullwhip effect can be defined as the distortion of the demand as it is transmitted up the chain (Lee et al 1997, p. 93). As an example, imagine a chain with customer, retailer, wholesaler, manufacturing company, and a first tier supplier. Each echelon of the chain forecasts its demand, considering its own process, information and uncertainties and orders goods from the upstream side of the chain. The result is that the demand at the supplier is highly unstable, even if the customer demand is stable at the retailer. The consequences of the bullwhip effect are: high levels of inventory, low customer service level and capacity and planning issues and constrains (Lee et al., 1997).

One of the main challenges for an efficient demand management is related to the interorganizational relationships. In order to share information, there must be trust and cooperation among its members, as well as coordination within an organization and between organizations. Otherwise, each firm will use safety stocks to protect against demand and supply uncertainties. (Lee et al., 1997).

Although several authors argue that the bullwhip effect cannot be avoided (Croxton et al., 2002; Dejonckhere et al .; 2003; Chatfield et al., 2004), there are several ways to mitigate it. Geary et al. (2006) list, based on extensive literature review, some principles that help to reduce the problem: control systems that measure the results of the chain, information sharing, reduced lead-times, shorter chains, synchronization between organizations, frequent demand forecasting and updating, joint planning with suppliers, optimization of batch production in order to reduce order quantities, avoidance of promotions and discounts ("everyday low price" strategy). Croxton et al. (2002) emphasize that, although the bullwhip is inevitable, the main goal of the demand management process is to implement some of the managerial practices that mitigate the issue and develop contingency plans to support a more effective and efficient customer service. To implement these practices along the whole chain it is important that all activities and processes are well coordinated in the SC.

\subsection{Supply Chain Coordination (SCC)}

Although SCC has been studied in the Operations and Supply Chain Management, it is still not a consensus between academics, with no unique definition (Arshinder \& Deshmukh, 2008). According to Sahin and Robinson (2002, p. 3), "a supply chain is fully coordinated when all decisions are aligned to accomplish global system objectives..". In order to be effective, decisions in a supply chain should be rationally taken to optimize supply chain results (Chen \& Xiao, 2009) and all activities and flow of goods and information have to be managed and controlled in order to create value to the final customer (Fugate et al, 2006). A literature review on the theme identified the definition of Malone and Crowston (1994) as the most commonly accepted: "the act of managing dependencies between entities and the joint effot of 
entities working together towards mutually defined goals" (Arshinder \& Deshmukh, 2008, p. 318).

It is important to highlight that coordination does not mean cooperation. While the previous concept is related to interaction, exchanges and alignment between members of a supply chain, the former is related to mutuality and collaboration and assumes a more close and commited relationship (Santos \& D'Antone, 2014). A coordination system defines processes and responsibilities inside the firm and at the interfaces of supply chain (Arshinder \& Deshumkh, 2008).

There are some key points that integrate the field: a) SCC assumes that there are different interdependencies and different type of conflicts between SC members; b) it is hard and complex to manage processes and activities between these organizations; c) there are different mechanisms that can be adopted in different chains and relationships; and d) there is a need to control if the coordination mechanisms is really effective (Arshinder \& Deshmukh, 2008).

Some of the mechanisms that can be used in a supply chain to implement coordination are supply chain contracts, information sharing, joint decision making and information technology (Arshinder \& Deshmukh, 2008). Li and Wang (2007) complement saying that centralized and decentralized supply chains require different mechanisms of coordination. While a centralized supply chain, that takes a systemic view with the main goal of a superior overall performance, can implement an action plan to control and integrate all activities and decisions, this is not true in a decentralized supply chain, where members adopt a more opportunistic behavior. In the last case, an incentive schema is necessary to motivate firms to cooperate (Li \& Wang, 2007). Xu and Beamon (2006) corroborate emphasizing that the appropriate coordination system (resource sharing structure, decision style, level of control and risk and reward sharing) depends on the interdependencies between organizations, uncertainty and information technology and results in different costs associated with coordination (coordination costs, operational risks costs and opportunistic risk cost).

The benefits of coordination are well known in the literature: inventory reduction, leadtimes reduction, increased customer satisfaction and revenue (Lee et al, 1997). However, managers fail to implement effective coordination due to different reasons that encompass human and procedures issues.
At the human perspective, coordination assumes interaction (i.e., good communication and personal relationships), exchange of information and resources and alignment to common goals (Santos \& D'Antone, 2014). However, many conflicts exist in the chain, such as individual goals and objectives, disagreement over leadership and different perspectives on decision making. Companies also differ in terms of organizational culture. On the other hand, SCC also depends on tools to monitor the actions and processes, such a unique performance measurement and cost evaluation systems; coherent contracts; frequent and regular information sharing; compatible information systems and agreement on practices such as order quantities, replenishment systems, frequency of deliveries, production cycles and batch sizes (Arshinder \& Deshmukh, 2008).

One gap identified in the SCC literature refers to how coordination can be affected by the evolution of the whole SC and external aspects such as institutional forces (Tang et al, 2008). According to Yaibuathet et al (2008, p. 262), "the IE (institutional environment) is one of the most significant factors for the achievement of SCM development" and considers both national settings and context. It is important to consider the relationship between institutions and the external environment, as organizations operate in different levels: country level, industry/sector level (macro), supply chain level (meso) and the firm level (micro) (Kinra \& Kotzab, 2008). The IE encompasses demands of government and regulatory bodies (regulative elements), society values and norms, normally associated to a country or region culture (normative elements) and cultural-cognitive that refers to a previously established "framework of individual society" (Yaibuathet et al. 2008, p. 263). Previous researches have provided evidence that IE influences integration (Cai et al., 2010; Wong \& Boon-itt, 2008), technology adoption (Zhang \& Dhaliwal, 2009) and highly influences the SC performance (Kinra \& Kotzab, 2008; Yaibuathet et al., 2008).

Bearing this in mind, this study aims to investigate the barriers for the lack of coordination in the Brazilian pharmaceutical supply chain, as discussed in the next section.

\section{METHODOLOGY}

A qualitative case study methodology was adopted as the research strategy in order to accomplish with 
the objectives. A case study can be defined as a as an empirical research methodology that investigates a contemporary phenomenon within its real context, especially when boundaries between phenomenon and context are not clearly evident (Yin, 1984). A deductive approach was selected with the purpose of theory elaboration (Kekovivi \& Choi, 2014), as the idea was to extend the previous knowledge about the phenomenon (coordination) complementing it with an institutional environment perspective (Barratt et al., 2011).

The unit of analysis in the present research was the supply chain as a whole. The Brazilian pharmaceutical supply chain (BPSC) was elected as the case for two main reasons. First of all, previous research has provided evidence of bullwhip effect and lack of coordination in Brazilian pharmaceutical chain (Miguel et al., 2009). As we would like to explore the hindrances of SCC, this is a obligatory requirement. Second, BPSC is one of the most important industries in Brazil and operates in the country since the 1900. Despite this, it is a very dynamic environment, with the entrance of new players and the influence of the government. The case is described in the next topic.

\subsection{Case description: Brazilian Pharmaceutical Supply Chain}

The pharmaceutical industry is one the most profitable sector in the worldwide economy, especially due to its high innovation rates, that represent a barrier to new entrants, either due to the process of patents registration or due to the high investments in research and development $(R \& D)$ required. It is also a regulated industry with high quality and reliability standards. Due to the limited number of players, the barriers to new competitors and the high profit margin, the industry does not prioritize efficiency (Capanema, 2006).

In Brazil, the pharmaceutical industry is responsible for an income of U\$ 25,5 billion in 2012 (ABIQUIM, 2013). It is a highly fragmented sector, but with sales concentration in a few players, mainly multinational companies - $60 \%$ percent international companies and $40 \%$ local companies according to Magalhães et al (2008). The operations consist normally in the production and distribution of drugs, with raw material being imported from other countries. Innovation activities are typically carried out abroad (Bastos, 2005).

The industry is highly regulated and prices are controlled by the government since 2001 (Romano et al, 2007). Products are also highly taxed - approximately $25 \%$ of sales revenue (Amaral, 2006).

In 2000, the Brazilian government authorized the production and sales of the so called generic drugs (i.e. a similar product or drug, which the patent protection has expired), increasing the competition of the sector and eliminating one of the most important barriers to new entrants (Capanema, 2006). In order to be competitive, leading companies have developed their own generic operations.

Figure 1 presents the Brazilian pharmaceutical supply chain. Industry is the focal company that is responsible for developing, producing and distributing the products in the market. The main suppliers are the chemical and pharma-chemical companies, as well as packaging suppliers. In Brazil, as the focal companies are normally subsidiaries of multinational companies, they also import raw material from other operations of their own corporation. Finished goods are distributed to retailers, through distributors and drugstore chains and are also sold to public and private cooperatives. 
Figure 1: Brazilian Pharmaceutical Supply Chain

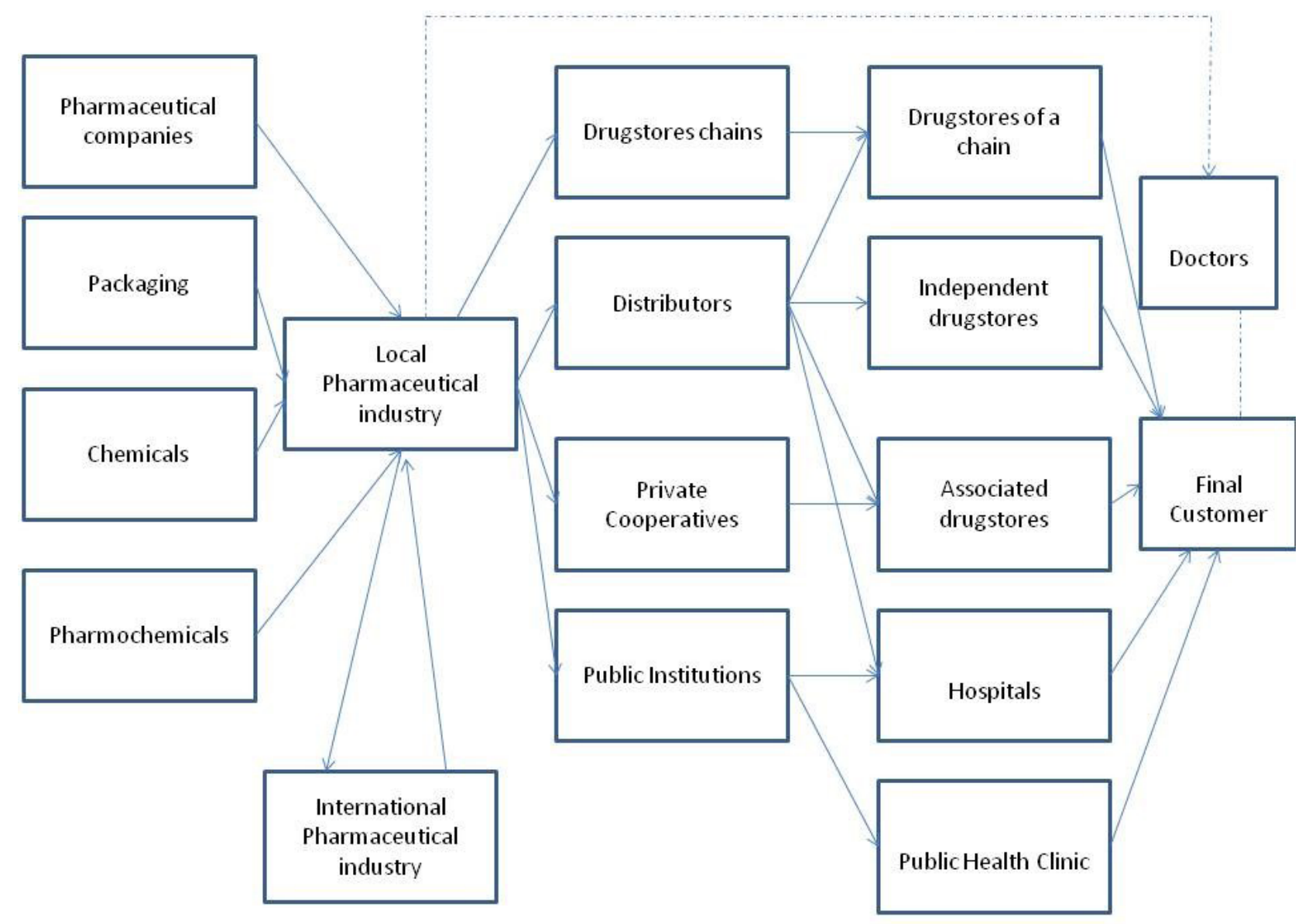

Source: Adapted from Miguel et al. (2009)

The pharmaceutical supply chain is structured in basically four nodes before the final consumer: Suppliers, Focal Company, Distributors and Retailers. In Brazil, there are between 50.000 to 70.000 point of sales (POS), highly sprayed in the whole country.

Although the pharmaceutical chains have national coverage, each geographic region presents different characteristics. The manufacturing operations are located basically in the Southeast region (Especially São Paulo and Rio de Janeiro). Major distributors have their operations in the Southeast, Midwest and Northeast regions, while in the North region, local distributors are responsible to fulfill orders to the point of sales, due to the logistical and transport constrains. From their Distribution Centers, the distributors are responsible to ship products to small and independent retailers.

With increased participation in the total market share, the drugstore chains are located in large cities and centers (mainly in SP and RJ). They purchase a large amount of goods from the focal companies and replenish inventory of their POS.

\subsection{Data collection and analysis}

During the research, 21 qualitative interviews with various companies and organizations in the supply chain were conducted from April 2010 to February 2011 (See tables 1 and 2 for the profile of respondents). Besides the main players in the supply chain such as suppliers, focal companies, distributors and drugstore chains, interviews were also conducted with 3 representative associations to have a broader view of the chain and with 2 service providers that assisted the companies with the Sales and Operations Planning procedures. Interviews took an average of 90 minutes and were recorded upon agreement of the respondents and transcribed for data analysis. 
Table 1: Profile of organizations

\begin{tabular}{l|r}
\hline Echelons in the supply chain & $\begin{array}{l}\text { Number of } \\
\text { interviews }\end{array}$ \\
\hline Suppliers & 4 \\
Focal companies & 4 \\
Distributors & 4 \\
Drugstore chains & 4 \\
Representative associations & 3 \\
Service Providers & 2 \\
Total & 21 \\
\hline
\end{tabular}

Source: Authors

Table 2: Profile of respondents

\begin{tabular}{l|r}
\hline Department & $\begin{array}{c}\text { Number of } \\
\text { interviews }\end{array}$ \\
\hline Business Strategy & 4 \\
Procurement & 5 \\
Sales/Commercial & 3 \\
SCM/Logistics & 5 \\
Operations & 1 \\
Finance & 1 \\
Consultant & 2 \\
Total & 21 \\
\hline
\end{tabular}

Source: Authors

During the data collection process, a semi-structured interview protocol was used (Appendix I). The interview consisted of two sections: 1) Questions about internal and intra-organizational relationships; 2) Questions about the internal process of each organization. No direct question on coordination was included to avoid bias from the respondents.

Each interview was analyzed concomitantly with the data collection in three steps. First, main ideas were extracted from the interview transcription; sec- ond, a more detailed analysis of the data identified context, condition and agents interactions and previous codes (A list of codes is presented in appendix II) were assigned ; finally, previously defined and new codes were classified in terms of the power of evidence provided (weak, moderate and strong). After each interview was analyzed, data were crossed to verify patterns, similarities and divergences (Collis \& Hussey, 2005, p. 247)

\section{DATA RESULTS}

The results of the data analysis were reported in three sections: Historical Evolution of the Brazilian Pharmaceutical Supply Chain, Internal Process and Intra-organizational relationships.

\subsection{Historical Evolution of the Brazilian Pharmaceutical Supply Chain}

Although the supply chain in Brazil is not new, it is in constant development. According to the interviewees, until the $80^{\prime} \mathrm{s}$, the focal companies were responsible for distributing products directly to the point of sales. Due to the increase of retailers and the need to invest in $R \& D$, there was a need to reconfigure the chain and the distributor node was included. The distribution function was outsourced and many employees of the industries started to lead the new operations and act as service provider.

In order to have economies of scales, the distributors could not be exclusive and they had to start working with different focal organizations. At this time, Brazil was facing high inflation and distributors started to make profit from speculative inventories: they purchased large quantities from the manufacturing and resold to retailers at a higher price. An additional incentive to the distributors was the fiscal war between the different regions of the countries. Their strategies were to prioritize fiscal gains instead of logistics efficiency. That resulted in a complex and unbelievable situation that made goods travel huge distances, without any need, increasing leadtime and therefore inventories at the different stages of the chain. At this time, distributors had three main activities: logistics, sales and credit that was a particularity of the Brazilian environment.

Until the decade of 1990, the pharmaceutical retailers were small point-of-sales, basically familiar business, with low professionalism. Those POS were called independent drugstores. In the 2000, 
however, those independent businesses started to form cooperatives or to be part of a drugstore chain. The existence of the independent POS, besides the lack of control, also promoted a parallel market of goods, with no control of inventories. Recently, however, the Brazilian government implemented the Electronic Fiscal Invoice and a new fiscal regime ("tax substitution regime") that forced the players to improve their processes and also to control better their business. Therefore the organizations that were making profit with the lack of control lost their bargaining power and size and had to redefine their strategies.

The distribution node also presented another peculiarity: the high competition between the organizations and the lack of practices and professional management resulted in a "just in time" customer service to retailer. According to respondents of this research, distributors had to deliver goods to POS daily, without a good system to manage inventory and transportation, resulting in higher operational costs and reduction of profitability. Many players in the industry had broken in the past years.

The industry was also been challenged with the new competition of generic drugs introduction. The reference industry lost their bargaining power, because distributors and suppliers now had new alternatives in the market. In order to overcome the competition, the focal companies were implementing two new strategies: 1) They were increasing their volume of sales to the drugstore chain, without the intermediation of the distributors; 2) They were implementing a new strategy, called Logistics Operations, in which their own sales representatives visit the biggest independent drugstores and offer products directly. When the POS places the order to the focal company, the order fulfillment is done through the distributor that is responsible only for the logistics operations. Although distributors claimed that the operation was not fair, the industry argued that they would like to be closer to the final consumer.

According to one of the independent drugstores, the logistics operation presents a trade-off between higher transparency and logistics organization and their ability to bargain in the purchasing process. According to one respondent, the practice improved the process but resulted in lower profitability.

Local suppliers of chemicals raw-materials were rare. In fact, the industry was almost broken due to the lack of governmental incentives and internation- al competition. Although new players were limited due to the ANVISA certification, products were imported from other countries, because import taxes were low, according to the interviewees. The packaging industry, on the other hand, was local and not exclusive. Packaging providers also supplied products to the Food and Cosmetics industries. According to the respondents, "the volume that they supply to the pharmaceutical industry is just a small portion of their portfolio, but it is highly profitable."

The dynamic evolution of the pharmaceutical supply chain and the regulation of the sector resulted in an environment that did not promote close relationships and efficiency, but foster opportunistic behavior. The new competition scenario with the entrance of new players (generic industry and drugstores chains) forced a new configuration of the network and also changed the bargaining power of the original players. In order to survive, they were competing against each other and were not open to collaboration. The pharmaceutical supply chain can be defined as a decentralized supply chain (Li \& Wang, 2007).

\subsection{Internal Process}

In the studied chain, the majority of the organizations did manage supply and demand independently and did not have process to synchronize them, although in some cases, both supplier management and demand management processes were functions developed in the same department. The respondents' reports provided evidence that companies were mainly concerned to achieve internal goals and were not focused on the chain as a whole.

According to one interviewee, although the whole industry was getting aware about logistics and supply management, there were still major conflicts between different departments within the company, avoiding internal integration. The employees of the organizations did not have a systemic and strategic view and had no interest to understand and to learn about the processes and activities performed by a different function, what might result in inefficiency. Another respondent believed that there was resistance inside organizations to promote internal integration. As he mentioned "people (in the industry) are not prepared to a shift in their own paradigm." The industry looked for new initiatives that would promote integration, but did not prepare their employees. Some of the reasons mentioned in the interviews were: no alignment 
with the HR department, lack of top management support and a short term view.

Another aspect that was constantly mentioned during the interviews was the lack of expertise in the industry, particularly in terms of logistics and planning. Several respondents mentioned high turnover in their organizations, driven by the competition with the generic manufactures. To reinforce the point, many of the respondents were pretty new in the organizations. Especially in the distributors, it was possible to notice that many of them were facing an internal reorganization and were hiring new employees from different sectors, aiming to increase competitiveness and bargaining power.

The interviews suggested that the pharmaceutical chain is deprived of skilled labor in logistics processes and supply chain management practices, although many companies were working to implement different tools. Only with the development of internal skills, the industry might achieve higher forecast accuracy and minimize the bullwhip effect. Processes such as Sales and Operations Planning (S\&OP), which were already being deployed in companies, would allow organizations to achieve internal alignment and consequently, external collaboration. Top management support would also be key in this process.

To minimize the bullwhip effect, the focal companies were taking two actions: a) contracting service providers that gathered information from retailers directly; b) improving their inventories control of finished goods, both internally and at the distributors, although inventory is still used as a bargaining tool. In terms of raw and packaging material, their main issue is related to imports clearance.

The distributors were also taking actions to survive. Driven by the challenges they had been facing, they were looking for new organizational structures and were reviewing processes to provide a new type of service.

Considering the discussion above, we can conclude that, because there is no internal integration in the companies, it is even harder to work with other organizations in the chain and therefore achieve SCC.

\subsection{Internal and Intra-organizational relationships}

As discussed before, the Brazilian pharmaceutical chain has not been planned for logistic efficiency or responsiveness and it was highly influenced by institutional aspects that provided higher bargaining power of the different links in the chain in different sectors.

The research suggested that the chain is characterized by lack of trust between the various links and almost none internal synchronization in business. In all interviews, it was found that there was no intention to cooperate with the other companies, although this was recognized as a best practice. The dispute for bargaining power between the various players and competition between firms within the same link are reflected in the lack of transparency and information sharing between the organizations.

The interviews also revealed that the government had influence on their operations, since regulation and tax regimes adopted in Brazil resulted in the need to take reactive actions. As examples, the law of generics increased competition and decreased the power of the reference laboratories and the increased fiscal control reduced the size of the distribution node.

As the interviews were conducted in the year of election to the presidency of the country, many respondents expressed uncertainty regarding measures that would affect the industry, such as the obligation to maintain the medicines behind the counters or the program called Popular Drugstores, created during the government of President Lula. According to several respondents, although the program has been presented as an alternative to the low-income population, the operationalization of the program has several limitations. One of the constraints was the certification of the authorized point of sales, as each outlet should be certified instead of the drugstore chain. According to the distributors' point of view, the government fostered closer relationships between industry and retail, disregarding the presence of distributors and encouraging the industry to operate directly with the retailer channel.

The conflict between industry and distributors was evidenced in the majority of the interviews with respondents of these ties. Although the industry was looking for logistics performance improvements using data collected directly with the retailers, they did not consider working closer to the distributors. Just as one example, one respondent mentioned that they were targeting to reduce days of inventory in the whole chain (industry and distributors), but they did not discussed that with their customers. 
When they believed that the inventory is high at the distribution level, they just interrupted the supply to them, without discussing products with excess inventory or shortages. This kind of approach is a consequence of their past history. Even when they claimed that they were trying to implement a closer relationship with drugstore chains, they did not provided any evidence that they were looking for integration. Companies were more focused on achieving internal goals.

According to the service providers interviewed, the goods are pushed through the chain and the lack of logistic expertise and an agreed leadership resulted in such conflicts. Just recently the players were getting aware of some of the best management practices discussed in the literature.

On the suppliers side, the lack of collaboration is also evident, but for different reasons. According to some of the interviewees, the volume of raw and packaging material that is sourced locally is quite low, compared to the total cost of material. Therefore, the industry does not have interest on developing and maintaining close relationships. The relationships, however, are less conflicting, perhaps due to the lower mutual dependence between the organizations. The qualified suppliers are protected by the certification process in the pharmaceutical supply chain. As ANVISA (the local FDA organization) control all products in this industry, the dyad can be classified in a "lock-in" situation.

It can be concluded that the existence of several participants in the pharmaceutical chain, competing against each other, has resulted in an associative or asymmetric supply chain, with high redundancy, i.e. there were many organizations supplying the same products and services, therefore, achieving the same costs, with low switching cost between suppliers / customers (Crook \& Combs, 2007; McCarter \& Northscraft, 2007). In this type of chain, each organization does its own activities independently of the other members of the chain and the bargaining power is usually concentrated in a single and stronger company, which appropriates the most gains of the supply chain.

According to Crook and Combs (2007), value can be created in a supply chain by each organization that contributes to individually and an extra share of value can be created by the synergy and interaction of the firms. The total value can be appropriated by the strongest organization or can be shared between each organization depending on the bargaining power of each party (Brandenburger \& Stuart, 1996, Coff, 1999; Bowman \& Ambrosini, 2003). This bargaining power depends on the resources available and control in the chain, as well as its structure and number of organizations (concentration) (Crook \& Combs, 2007). If the firm has access to information, it can estimate the interdependencies of all members and it might capture a larger share of the gains during negotiations (Crook \& Combs, 2007). In the studied case, because the bargaining power is under discussion, the organizations were not willing to cooperate and coordinate activities.

According to the interviews, the most profitable tie in the chain was the focal companies, responsible for the product development and manufacturing. Their high margins were the value appropriated by them and it was created by the industry individually. Local suppliers did not add much value to the final product, as the most important raw material came from foreign countries. The distributors and drugstore chains margins were also quite irrelevant to the total value created, and their value creation came from logistics and fiscal processes.

As the focal company could only deploy its products to the market through distributors for a long time, the bargaining power of the distributors increased and the focal companies had to share the leadership and the gain with this tie. However, the status of the distributors weakened when the inflation got controlled, the government started to improve the fiscal control and the industry had a new alternative to sell product (drugstores chains). The focal company, also, was impacted by the release of generic production in Brazil. So both echelons in the pharmaceutical network had to readapt to a new scenario to recover their gains and were working individually, competing with the other tie to increase their own bargaining power.

The history of the chain had also shown that companies always adopted an opportunistic behavior, resulting in the lack of trust. Therefore, there was no information sharing, because access to information could mean more bargaining power and more value appropriation. The companies did not foresee the benefits of working in a collaborative manner.

The previous results can be regrouped according to the literature of SCC and institutional perspectives on SCM as shown in figure 2. Besides the traditional barriers, this research provided evidence 
of news force that inhibits the SCC: the dynamics of the environment that forces the organizations to adapt themselves to new constrains in the system in order to achieve a new optimal point and the in- fluence of the macro infrastructures on the SCM, such as politics, economy culture, that is better understood by institutional perspectives (Tang et al. 2008).

\section{Figure 2: Barriers to SCC}

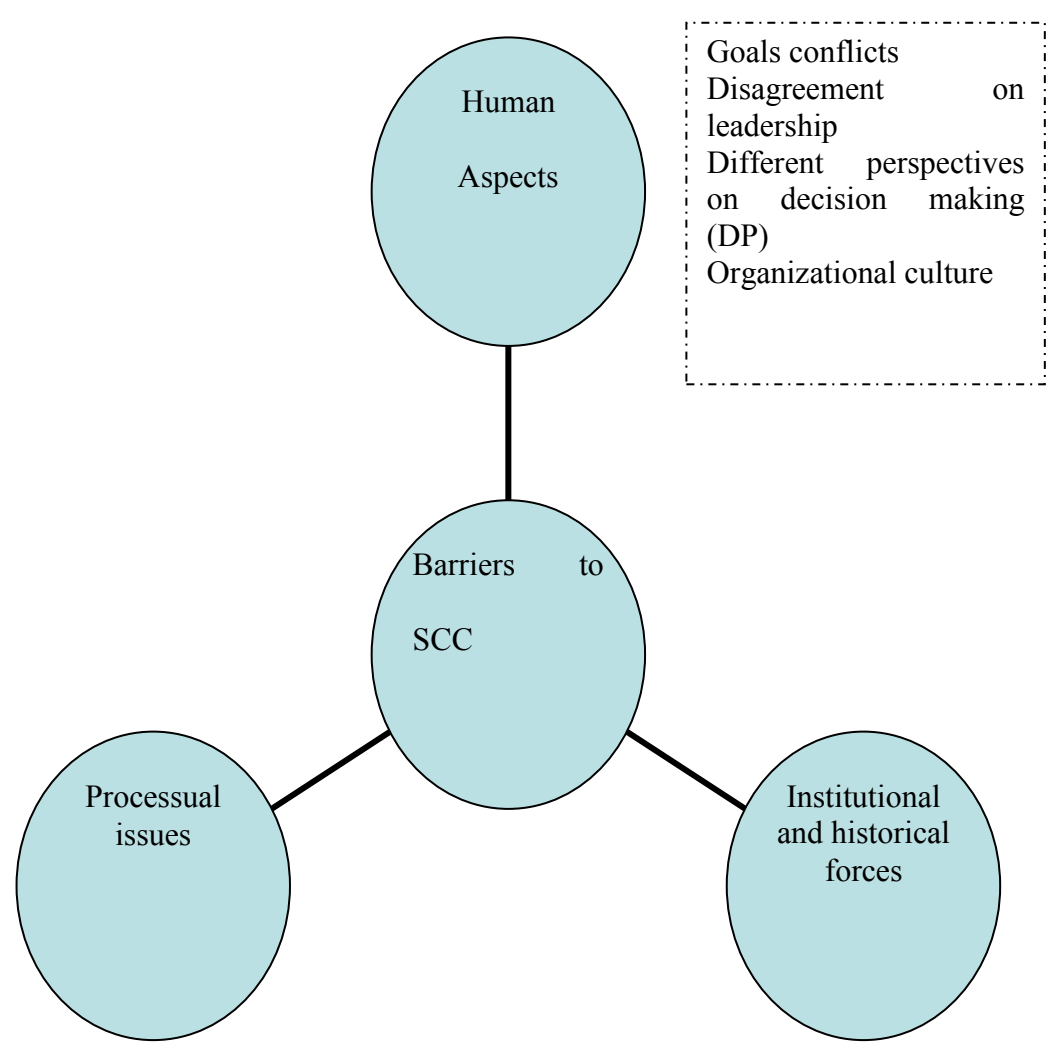

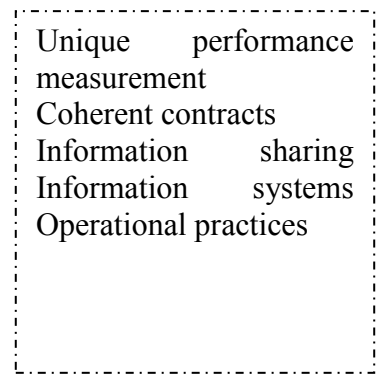

The proposed framework can also be analyzed according to the institution level as suggested by Kinra \& Kotzab (2008). While the traditional barriers exist at the micro or meso level (i.e, organization and supply chain), the new forces refer to the macro level (country level) that influences the environmental complexity and change the constraints perceived by each firm (Kinra \& Kotzab, 2008).

\section{CONCLUSIONS}

Aiming to understand the lack of coordination and the resulted bullwhip effect in the pharmaceutical supply chain, this research adopted a case study approach. The results suggest that the mainly causes of a poor demand management process were: a network designed to achieve fiscal efficiency instead of 
logistics efficiency, dispute for bargaining power in order to appropriate more value, resulting in low levels of confidence and lack of internal resources and skills to better manage processes internally and with other companies in the chain.

Compared to challenges to SCC mentioned in the literature section - dominant member in the chain that takes decisions, different organizational culture, lack of coherent contracts, lack of meetings and commitment, incompatible information systems, conflicting objectives, independent cost evaluation of activities and processes, etc (Arshinder \& Deshmukh, 2008) - this research provided evidence that SCC is also affected by the past experience of the organizations with suppliers and distributors and by institutions environment.

By analyzing the whole chain instead of just a dyad as the majority of SCC researches, this study contributes the theme debate by confirming the traditional barriers to coordination but also findings suggest that institutional and environment forces can act as barriers to an effective coordination of the supply chain. For managers, the paper provides a tool to identify what are the main aspects that should be surpassed to manage effectively processes and activities across organizations in a supply chain.

The research has some limitations. Firstly, the focus was given to multinational drug product reference industry. The research was limited to companies with operations mainly in the Southeast and South. No interview was conducted with companies with the highest performance in the North or Northeast. As the pharmaceutical market is highly regionalized, additional features should be found in these regions.

Moreover, because it is a case study, the results of this research are limited to companies that participated in the interviews, No generalization should be made.

\section{REFERENCES}

Amaral, G. L. (2006). Radiografia da Tributação sobre Medicamentos: Carga Tributária Incidente no Setor Farmacêutico. São Paulo: Federação Brasileira da Indústria Farmacêutica (Febrafarma).

Arshinder, A. K.\& Deshmukh, S.G., (2008) Supply chain coordination: Perspectives, empirical studies and research directions, International Journal of Production Economics, v. 115, p. 316-335.

ASSOCIAÇÃO BRASILEIRA DA INDÚSTRIA QUÍMICA (ABIQUIM). (2014) A Indústria Química - Estatísticas. http://www. abiquim.org.br/conteudo.asp. Accessed in November 04th.
Barratt, M., Choi, T. Y., \& Li, M. (2011). Qualitative case studies in operations management: trends, research outcomes, and future research implications. Journal of Operations Management, 29(4), 329-342.

Bastos, V. D. (2005) Inovação Farmacêutica: Padrão Setorial e Perspectivas para o Caso Brasileiro. BNDES Setorial, n. 22, p. 271-296.

Bowman, C. \& Ambrosini, V. (2000). Value Creation Versus Value Capture: Towards a Coherent Definition of Value in Strategy. British Journal of Management, 11(1), 1-15.

Brandenburger, A. M., \& Stuart, H. W. (1996). Value-based Business Strategy. Journal of Economics \& Management Strategy, $5(1), 5-24$.

Capanema, L. X. L. (2006) A Indústria Farmacêutica Brasileira e a Atuação do BNDES. BNDES Setorial, n. 23, p. 193-216.

Chen, I. J.\& Paulraj, A. (2004) Towards a Theory of Supply Chain Management: The Constructs and Measurements. Journal of Operations Management, v. 22, n. 2, p. 119-150.

Coff, R. W. (1999). When competitive advantage doesn't lead to performance: The resource-based view and stakeholder bargaining power. Organization Science, 10(2), 119-133.

Cooper, M. C.\& Ellram, L. M. (1993) Characteristics of Supply Chain Management and the Implications for Purchasing and Logistics Strategy. The International Journal of Logistics Management, v. 4, n. 2, p. 13-24..

Cooper, M. C.; Lambert, D. M. \& Pagh, J. D. (1997) Supply Chain Management: More Than a New Name for Logistics. The International Journal of Logistics Management, v. 8, n. 1, p. 1-14.

Crook, T. R., \& Combs, J. G. (2007). Sources and consequences of bargaining power in supply chains. Journal of Operations Management, 25(2), 546-555. doi: 10.1016/j.jom.2006.05.008

Croxton, K. L. et al. (2002) The Demand Management Process. The International Journal of Logistics Management, v. 13, n. 2, p. 51-66, 2002.

Forrester, J. W. Industrial Dynamics. Cambridge, Mass: Massachusetts Institute of Technology, 1961.

Fugate, B., Sahin, F. \& Mentzer, J.T., (2009) Supply chain coordination mechanisms, Journal of Business Logistics, v. 27 (2), p. 129-161.

Geary, S.; Disney, S.M.\& Towill, D.R. On bullwhip in supply chains - historical review, present practice and expected future impact. International Journal of Production Economics, v. 101, p. 2-18, 2006.

Holweg, M.; Disney, S.; Holström, J.\& Smaros, J. Supply Chain Collaboration: Making Sense of the Strategy Continuum. European Management Journal, v. 23, n. 2, p. 170-181, 2005.

Ketokivi, M.\& Choi, T. (2014) Renaissance of case research as a scientific method. Journal of Operations Management, v. 32, p. 232-240.

Kinra, A.\& Kotzab, H. (2008) A macro-institutional perspective on supply chain environmental complexity. International Journal of Production Economics, v.115, p. 283-295. 
Miguel, P. L. S., Reis, M. A. S.: Coordination in Brazilian Pharmaceutical Supply Chains ISSN: 1984-3046 - Journal of Operations and Supply Chain Management Volume 7 Number 2 p 75 - 90

Lambert, D.; Cooper, M. C.\& Pagh J. D. (1998) Supply Chain Management: Implementation Issues and Research Opportunities. The International Journal of Logistics Management, v. 9, n. 2, p. 1-19.

Lee, H. L.; Padmananhan, V.\& Whang, S. (1997) The Bullwhip Effect in Supply Chains. Sloan Management Review, p. 93-102, Spring.

Li, X. \& Wang, Q. (2007) Coordination Mechanisms of supply chian systems, European Journal of Operational Research, v. 179, p. 1-16.

Magalhães, J.L; Boechat, N. \& Antunes, A.M.S.(2008) An overview of the Brazilian pharmaceutical production status. Chemistry Today, v. 26 (4).

Mentzer, J. T. et al. (2001) Defining Supply Chain Management. Journal of Business Logistics, v. 22, n. 2, p. 1-25.

Miguel, P.L.S.; Reis, M.A.\& Pignanelli, A. (2009) Gestão da Demanda em Cadeias Farmacêuticas Brasileiras: Um estudo de Casos Múltiplos. In Encontro de Anpad, 2009, São Paulo. XXXIII Encontro da Anpad.

Romano, L. A. N.; Pelajo, M. A.\& Silva, M. A. C. (2007) Análise de Desempenho Econômico-

Financeiro do Setor Farmacêutico no Brasil: 2003 a 2005. São Paulo: Federação Brasileira da Indústria Farmacêutica (Febrafarma).
Sahin, F.\& Robinson, E.P. (2002) Flow Coordination and Information Sharing in Supply Chains: Review, Implications and Directions for Future Research, Decision Scineces, v. 13 (4), p. $1-32$.

Santos, J.B.\& D'Antone, S.A. (2014) Reinventing the wheel? A critical view of demand-chain management., Industrial Marketing Management, v. 43, p. 1012-1025.

Tang, O., Cao D.\& Schvaneveldt, S. J. (2008) Editorial Institutional perspectives on supply chain management. International Journal of Production Economics, v.115,p. 261.

Taylor, D. H. (2006) Demand Management in Agri-Food Supply Chains: An Analysis of the

Characteristics and Problems and a Framework for Improvement. The International Journal of Logistics Management, v. 17, n. 2, p. $163-186$.

Xu, L.\& Beamon, B.M. (2006). Supply chain coordination and cooperation mechanisms: An attribute-based approach, The Journal of Supply Chain Management, Winter, p. 4-12.

Yaibuathet, K; Enkawa, T.\& Suzuki, S. (2008)Influences of institutional environment toward the development of supply chain management. International Journal of Production Economics, v.115,p. 262-271.

Yin, R. K. Case Study Research: Design and Methods (2nd ed.), Newburry Park: Sage Publications, 1984 


\section{APPENDIX I - INTERVIEW PROTOCOL}

Name of interviewer:

Function:

\section{Section 1 - Internal and intra-organizational rela- tionships}

1. Could you explain your role in the relationship between your organization and other companies in the chain?

2. In your perspective, how was the historical evolution of your organization's echelon in the Brazilian pharmaceutical supply chain?

3. In your opinion, which is the most powerful echelon in this supply chain? Are companies dependent of each other?

4. How do you describe the chain in terms of commercial issues? How are the price and conflict negotiated with customers? And what about suppliers?

5. Could you explain how are the internal relationships in your organization? Do different departments share the same objectives and vision?

6. How do you define the intra-organizational relationships in the chain? Do you describe them as collaborative or competitive?

7. The pharmaceutical supply chain is known as very profitable. How is this profit shared between organizations in the chain?
Organization:

Since:

\section{Section 2: Internal process of each organization.}

8. Who is responsible for demand and supply management in your organization? Are demand and supply synchronized in your company? How?

9. What are the mains sources of inventory in this organization? What are the key issues? How does demand variability impact inventory management?

10. Could you briefly describe incentives and discounts programs adopted by this company? Do these programs impact the demand profile?

11. How does the government regulation affect your demand management process (consider Anvisa, price control, fiscal benefits)?

12. Is there any initiative for technology integration in the chain? With whom? Which are the objectives?

13. In your opinion, how could the demand management process be improved? Would this process improvement have impact performance? 


\section{APPENDIX II - LIST OF CODES}

Goals and Objectives Conflicts (GOC)

Leadership (L)

Different perspectives on decision making (DP)

Organizational culture (OC)

Unique performance measurement (PM)

Coherent contracts (CC)

Information sharing (IS)

Information systems (IS)

Operational practices (OP)

Internal synchronization (IS)

Intraorganizational integration (II)

Bargaining power (BP)

Dependency (D)

Government influence (GI)

Supply chain history $(\mathrm{SCH})$ 


\section{AUTHOR'S BIOGRAPHY:}

Priscila Laczynski de Souza Miguel : has graduated in Chemical Engineer by Unicamp and has done her Master and PhD in Business Administration in FGV-EAESP. Currently she is a Lecturer at Operations Management Department at FGV-EAESP and is researcher at the Center of Excellence in Logistics and Supply Chain FGV (GVCELog). Her interests are: Logistics, Supply Chain Management, Buyer-Supplier Relationships and Operations in Natural Disasters.

Manoel A. S. Reis: Holds Bachelor and Master degrees in Naval Architecture from the Polytechnic School of the University of Sao Paulo, Brazil, and a Ph.D degree from the Massachusetts Institute of Technology - MIT - USA.

At Getulio Vargas Foundation in Sao Paulo, Dr. Reis is a Professor of Logistics and Supply Chain, Director of the Center for Logistics and Supply Chain Studies (GVcelog), and Coordinator of the courses Master in Logistics and Supply Chain and continuing education Business Logistics. 